\title{
Risk Analysis Method for Flood Control Operation of Cascade Reservoirs Considering Prediction Error
}

\author{
Yan-Ke ZHANG ${ }^{1, a}$, Jin-Jun YOU ${ }^{2, b,{ }^{*}}$, Chang-Ming $\mathrm{JI}^{1, \mathrm{c}}$ and Ya-Wei ZHAO ${ }^{1, \mathrm{~d}}$ \\ ${ }^{1}$ School of Renewable Energy, North China Electric Power University, Beijing 102206, China \\ ${ }^{2}$ China Institute of Water Resources and Hydropower Research, Beijing 100044, China \\ aykzhang2008@163.com, byoujj@iwhr.com, ccmji@ncepu.edu.cn, dyaweizhao2017@126.com \\ ${ }^{*}$ Corresponding author
}

Keywords: Prediction error, Cascade reservoirs, Flood control, Risk analysis.

\begin{abstract}
Due to the existence of runoff randomness, flood control operation of cascade reservoirs faces certain risk. In this paper, risk evaluation's index system for the objectives of cascade reservoirs is established. And based on the normal quantization of accidental error in flood prediction, a flood stochastic simulation method is proposed within the allowable standard deviation. Through the classification of flood frequency, a risk analysis for flood control model and its solving method with Monte Carlo and maximum entropy theory were also constructed. By analyzing the joint flood operation of Three Gorges and Xiluodu, it shows that the method and model is reasonable, feasible and has a certain degree of adaptability. Especially it can estimate the threshold of flood forecast error standard deviation according to its own downstream capacity of flood diversion area and decision-makers’ preferences, and provide an important basis for the scheduling decision.
\end{abstract}

\section{Introduction}

Researches and practices on joint operation of cascade reservoirs are becoming more and more in order to increase the comprehensive utilization benefits at present (Chih-Chiang Wei et al. 2008; Peng Y et al.2004; Fu G T 2008; Huang Q et al. 1996; Wang D et al. 2001). However, the effects of many uncertain factors, such as hydrology, hydraulic, engineering structures and human factors (Jiang Zhang et al. 2007; Kyungrock Paik 2008; R. O. Thomsen et al. 1997; Diao Y F et al. 2010), make the comprehensive utilization benefits of cascade reservoirs a certain risk or affected at different degree. The most difficult thing for joint flood control of cascade reservoirs is the uncertainty of flood process, in addition to the features of different geographical locations, functional structures, operation modes and objectives; flood control becomes more complex and difficult. Therefore, to carry out risk analysis for joint flood control of cascade reservoirs operation is important to improve the maximum benefits of cascade reservoirs. Risk analysis generally includes four stages: risk identification, risk estimation, risk evaluation, risk decision, and two important factors should be determined in the first two stages in risk analysis, that is risk factors and risk indexes. For flood control operation, the major influencing factor for making scheduling decision is the uncertainty runoff. Though the predicting flood process has provided important basis to decision makers for actual flood control of cascade reservoirs with runoff prediction system, the uncertainty of prediction is still a factor that we should not ignore. If the prediction flood is larger which pay more attention to the flood control safety, it may waste a large number of water resources and affect the utilizable benefits; and if the prediction flood is smaller which pay more attention to improve the utilizable benefits, it may affect the flood control safety. Prediction error is a main index to reflect the uncertainty of flood prediction and an important factor that need considering in flood control decision. At present, there are less achievements of joint flood control of cascade reservoirs by considering flood prediction error. It is known that some researchers have studied the single reservoir's dynamic control with different beginning regulation levels in flood season (Xiang Liet al. 2010). Some other researchers have proposed the corresponding risk indexes (K. R. Suresh et al. 2004). Few people have proposed the effectively available risk index system and risk analysis model. Therefore, risk 
analysis model for joint flood control of cascade reservoirs is established by considering flood prediction error and flood frequency levels on the basis of building joint flood control risk index system of cascade reservoirs in this paper,. It is tested and analyzed to take the joint flood control of Xiluodu and Three Gorges cascade reservoirs as an example.

\section{Joint Flood Control Risk Index System of Cascade Reservoirs}

Suppose that there are $m$ reservoirs in cascade reservoirs, and risk rate of flood control for reservoir $i$ itself is:

$$
P_{r-i}=\operatorname{Pr}\left(\max \left(Z_{i}(t)\right)>Z_{a-i}\right)
$$

Where $Z_{i}(t)$ is the water level of reservoir $i$ at period $t ; Z_{a-i}$ is the safety water level of reservoir $i$.

As for joint flood control of cascade reservoirs, the loss will be great once the dam itself damaged, therefore, firstly to ensure the reservoir with the maximum risk rate of flood control is safety, and the risk rate of flood control of cascade reservoirs is:

$$
P_{r}^{c q}=\max \left(P_{r-i}\right) \quad i=1,2, \cdots, m
$$

Where $P_{r-i}$ represents the risk rate of flood control of reservoir $i$.

The key point of joint flood control of cascade reservoirs is the common flood control protecting area (assuming there is only one). However, for each reservoir itself the requirements of flood control protection area can be considered as constraint condition, thus, for the control point of common flood control protecting area, we define the probability that its flow exceeds safety discharge is the risk rate of flood control of common flood control protecting area of cascade reservoirs, that is:

$$
P_{d}^{c q}=\operatorname{Pr}\left(\max \left(q^{c q}(t)\right)>q_{a}^{c q}\right)
$$

Where $q^{c q}$ represents the flow at common flood control point, $\mathrm{m}^{3} / \mathrm{s} ; q_{a}{ }^{c q}$ represents the safety discharge at common flood control point, $\mathrm{m}^{3} / \mathrm{s}$.

Joint flood control of cascade reservoirs also needs to consider the utilizable benefits, and more important thing is to make sure that the water level of reservoirs (assuming there are $m_{1}$ reservoirs) which are at the end of the flood control when the flood control is finished can reach to normal storage level. Suppose $P_{x s-i}(i=1,2 \ldots m 1)$ is the water storage deficiency risk rate of the $m_{1}$ reservoirs respectively, and the water storage deficiency risk rate of cascade reservoirs is:

$$
P_{x s}^{c q}=\max \left(P_{x s-i}\right)
$$

Another index affecting flood control safety of reservoirs is that, the water level of reservoirs (assuming there are $m_{2}$ reservoirs) which are not at the end of the storage period when the flood control operation is finished should be within the set range so as not to cause loss if they encounter the follow-up flood. Suppose $Z_{L-i}, Z_{M-i}\left(i=1,2, \ldots, m_{2}\right)$ is the lower and upper limits of water level control of reservoir $i$ at the end of joint flood control, and the risk rate of water level control below standard of joint flood control of reservoirs is:

$$
P_{d b}^{c q}=\max \left(P_{d b-i}\right)
$$

Where $P_{d b-i}$ represents risk rate of water level control below standard of reservoir $i$.

To sum up, expression of (2)(3)(4)(5) form the joint flood control risk index system of cascade reservoirs. 


\section{Joint Flood Control Risk Analysis Model of Cascade Reservoirs}

\section{Flood Prediction Error Quantization}

RealQ and forecastQ represent the measured value and the predicted value respectively, and define $X=($ realQ-forecast $Q) /$ realQ is the prediction error, and then the value of prediction error is reflected by the approaching degree between $X$ and zero. Suppose $x_{1}, x 2 \ldots x n$ is the sample of $X$, there is:

$$
f(X)=\frac{1}{\sqrt{2 \pi} \sigma_{X}} e^{-\frac{\left(x-\mu_{X}\right)^{2}}{2 \sigma_{X}{ }^{2}}}
$$

Where $x_{i}=\frac{\left(\text { forecast }_{i}-\text { real }_{i}\right)}{\text { real }_{i}} \quad i=1,2, \cdots, n$.

It is easy to obtain maximum likelihood estimation of parameters $\mu_{X}, \sigma_{X}$, they are:

$$
\mu_{X}=\frac{1}{n} \sum_{i=1}^{n} x_{i}, \quad \sigma_{X}=\sqrt{\frac{1}{n} \sum_{i=1}^{n}\left(x_{i}-\mu_{X}\right)^{2}}
$$

Thus, error series $X$ can be generated randomly by Monte Carlo simulation after parameters $\mu_{X}, \sigma_{X}$, are obtained by analyzing historical prediction information, and then the flood process can be obtained with considering flood prediction error according to the formula realQ=forecast $Q /(1-X)$, at last flood process of a certain frequency can be gotten by zooming the flood process.

\section{Joint Flood Control Risk Analysis Model of Cascade Reservoirs Considering Flood Prediction Error}

\section{Model Establishment}

All manuscripts must be in English, also the table and figure texts, otherwise we cannot publish your paper.

Please keep a second copy of your manuscript in your office. When receiving the paper, we assume that the corresponding authors grant us the copyright to use the paper for the book or journal in question. Should authors use tables or figures from other Publications, they must ask the corresponding publishers to grant them the right to publish this material in their paper.

After obtained flood series Simulate $Q_{i}(i=1,2 \ldots n)$ considering flood prediction error, each risk index value can be calculated by joint flood control calculation and statistical analysis. However, for joint flood control of cascade reservoirs, because flood control is more important than profiting, the risk indexes exist the relationship $P_{r}^{c q}>P_{d}^{c q}>P_{d b}^{c q}>P_{x s}^{c q}$. The risk analysis purpose of joint flood control of cascade reservoirs is to decrease loss as little as possible and improve the maximum utilizable benefits in the condition of reservoirs flood control safety. It mainly reflects that when cascade reservoirs face different frequency flood the emphasis points are different. When encountering design frequency flood of downstream protection area, we should make sure that the flood control loss is the least. When encountering design frequency flood of dam, we should pay more attention to dam safety. When encountering the flood less than a certain frequency flood it should be ensure to improve utilizable benefits as much as possible. Therefore, to anastomosed the final purpose of joint flood control of cascade reservoirs, flood control risk should have the special meanings aiming to different frequency flood when joint flood control risk analysis of cascade reservoirs. Considering flood control risk according to flood frequency classification, joint flood control risk of cascade reservoirs can be described as follows: 


$$
P=\left\{\begin{array}{l}
P_{r}^{c q}=\max \int_{Z_{a-i}}^{+\infty} f_{r}\left(Z_{i}^{M}\right) d Z_{i}^{M} \quad p \geq p_{d s} \\
P_{d}^{c q}=\int_{q_{a}^{c q}}^{+\infty} f_{d}\left(q_{m}\right) d q_{m} \quad p_{d s}>p \geq p_{x y} \\
P_{x s}^{c q}=\max \int_{Z_{N-i}}^{+\infty} f_{x y}\left(Z_{i}^{L}\right) d Z_{i}^{L},\left(i=1,2, \cdots, m_{1}\right) \quad p_{x y}>p>0 \\
P_{d b}^{c q}=\max \int_{Z_{L-i}}^{Z_{M-i}} f_{d b}\left(Z_{i}^{L}\right) d Z_{i}^{L},\left(i=1,2, \cdots, m_{2}\right) \quad p>0
\end{array}\right.
$$

Where $Z_{i}{ }^{M}$ is the highest dam water level of reservoir $i . q_{m}$ is the maximum discharge flow of the common flood control point; $Z_{i}^{L}$ is the water level at the end of flood control of reservoir i.p= $\left(p_{1}, p_{2}, \ldots, p_{m}\right)$ is the frequency that each reservoir faces. $p_{d s}=\left(p_{d s 1}, p_{d s 2}, \ldots, p_{d s m}\right)$ is the design flood frequency vector of each reservoir dam. $p_{x y}=\left(p_{x y 1}, p_{x y 2}, \ldots, p_{x y m}\right)$ is design flood frequency vector of downstream. $f_{r}(\bullet), f_{d}(\bullet), f_{x y}(\bullet), f_{d b}(\bullet)$ are the distribution density functions corresponding each variable.

\section{Model Solution}

In general case, joint flood control risk calculation of cascade reservoirs is almost little probability events. And it need a large number of numerical calculation using Monte Carlo, but it may waste a lot of time for joint operation calculation of multi-reservoirs and it isn't useful for actual operation, so simulated maximum entropy method(SMEM) (Wang L P et al. 2011) is introduced in order to improve calculating speed. The solving steps are described as follows:

(1)Simulate flood process series $n$ times based on historical flood prediction information:

$$
\left[Q_{i j}(t)\right](i=1,2, \cdots, m ; j=1,2, \cdots, n ; t=1,2, \cdots, T)
$$

Where $T$ is the time period number of joint flood control. [ $\left.Q^{\prime}{ }_{i j}(t)\right]$ can be obtained by zooming $\left[Q_{i j}(t)\right]$ to the frequency $p$, and the dam water level process series $Z_{i j}(t)$, discharge flow series of common flood control point and dam water level value $Z^{L}{ }_{i j}$ at the end of the joint flood control, can be gotten after flood regulating ;

(2)Let $Z^{M}{ }_{i j}=\max Z_{i j}(t)$ and $q^{M}{ }_{j}=\max q_{j}(t)$, then $Z^{M}{ }_{i j}, q^{M}{ }_{j}, Z^{L}{ }_{i j}\left(i=1,2 \ldots m_{1}\right)$ and $Z^{L}{ }_{i j}\left(i=1,2 \ldots m_{2}\right)$ represent $n$ sample points corresponding $n$ simulated flood process of reservoir $i$;

(3)Use the method of SMEM to Solve $f_{r}(\bullet), f_{d}(\bullet), f_{x y}(\bullet), f_{d b}(\bullet)$;

(4)Calculate joint flood control risk rate $P$ of cascade reservoirs with appointed frequency $p$ and model expression (8).

\section{Case Study}

\section{Cascade Reservoirs Situation}

Xiluodu and Three Gorges are two large-scale reservoirs on mainstream of the upper and middle Yangtze River; they are both designed for 1000-year flood and checked for 10000-year flood, and both undertake flood control task of downstream area in flood season. Xiluodu reservoir intercepts Jinshajiang flood in flood season that decreases flood volume into Three Gorges reservoir directly, it can decreases flood control pressures further of Zhicheng and Chenglingji which are flood control points of upper and middle Yangtze river matching Three Gorges reservoir operation. For Xiluodu reservoir, normal water level is $600 \mathrm{~m}$, limited water level during flood season is $560 \mathrm{~m}$, and dead water level is $540 \mathrm{~m}$, regulating storage is 6.46 billion $\mathrm{m}^{3}$, flood control capacity is 4.65 billion $\mathrm{m}^{3}$, and it has incomplete yearly regulation capability, flood season is from June to first ten days of September. For Three Gorges reservoir, normal water level is $175 \mathrm{~m}$, limited water level during flood season is $145 \mathrm{~m}$, and dead water level is $155 \mathrm{~m}$, regulating storage is 16.5 billion $\mathrm{m}^{3}$, flood control capacity is 22.15 billion $\mathrm{m}^{3}$. Three Gorges reservoir is putting flood control first, and power generation should obey flood control. For the need of flood control, water level should decrease to limit level $145 \mathrm{~m}$ gradually from the end of May to the first ten days of June. And it generally keep operate with $145 \mathrm{~m}$ from middle June to the end of September, when flood comes, reservoir intercepts 
flood and water level goes up; after the flood reservoir should be cleaned clear for the next flood peak. In October after flood season, reservoir stores water and water level goes up to $175 \mathrm{~m}$ gradually.

\section{Flood Process Simulation of Cascade Reservoirs}

We estimate and analyze standard deviation of flood prediction error in the possible range in order to decrease sample error due to the limitation of historical prediction information. Moreover, flood process of Three Gorges reservoir and Xiluodu reservoir considering prediction error is simulated by using flood prediction error of Three Gorges as control, where inflow flood process of Xiluodu reservoir is obtained by zooming historical flood process in proportion in order to accord with practical situation, and specific simulating process is shown in Figure 1.

Maximum 30-day flood volume, peak error statistics about simulated inflow flood process of Three Gorges are shown in Table 1, and it can be concluded that maximum 30-day flood volume error is not more than $1 \%$ and peak error is within $1000 \mathrm{~m}^{3} / \mathrm{s}$ by data statistics which accords with actual prediction operation statistics situation.

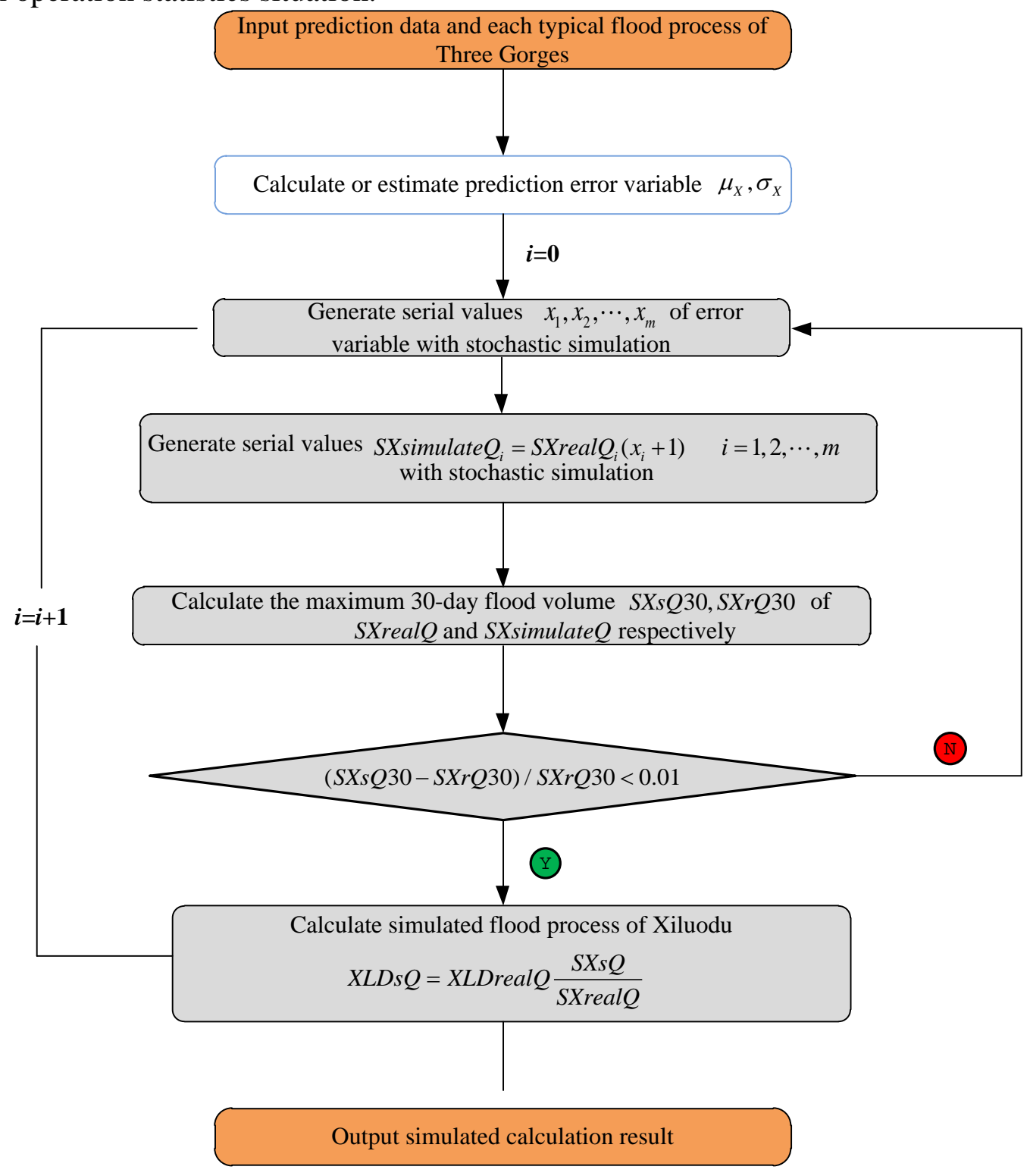

Fig. 1 Flood process simulation flow chart of Xiluodu and Three Gorges joint operation 
Table 1 Maximum 30-day flood volume, peak error statistics with simulated inflow flood process of Three Gorges

\begin{tabular}{|c|c|c|c|c|c|c|}
\hline $\begin{array}{c}\text { Flood } \\
\text { simulation } \\
\text { times }\end{array}$ & $\begin{array}{c}\text { Measured } \\
\text { maximum } \\
\text { 30-day flood } \\
\text { volume } \\
\text { actually } \\
{\left[100 \text { million }^{3} \text {. }\right.} \\
\mathrm{m}^{3}\end{array}$ & $\begin{array}{c}\text { Measured } \\
\text { peak } \\
\text { actually } \\
{\left[\mathrm{m}^{3} / \mathrm{s}\right]}\end{array}$ & $\begin{array}{c}\text { Simulate } \\
\text { maximum } \\
\text { 30-day flood } \\
\text { volume[100 } \\
\left.\text { million } \mathrm{m}^{3}\right]\end{array}$ & $\begin{array}{c}\text { Simulate } \\
\text { peak } \\
{\left[\mathrm{m}^{3} / \mathrm{s}\right]}\end{array}$ & $\begin{array}{c}\text { Flood volume } \\
\text { relative error } \\
{[\%]}\end{array}$ & $\begin{array}{c}\text { Peak error } \\
{\left[\mathrm{m}^{3}\right]}\end{array}$ \\
\hline 1 & 1363.2192 & 61700 & 1364.5628 & 61773 & 0.0986 & 73 \\
\hline 2 & 1363.2192 & 61700 & 1363.5465 & 62434 & 0.0240 & 734 \\
\hline 3 & 1363.2192 & 61700 & 1361.7354 & 62357 & -0.1088 & 657 \\
\hline$\ldots$ & $\ldots$ & $\ldots$ & $\ldots$ & $\ldots$ & $\ldots$ & $\ldots$ \\
\hline 19997 & 1363.2192 & 61700 & 1360.9292 & 61670 & -0.1680 & -29 \\
\hline 19998 & 1363.2192 & 61700 & 1364.1799 & 61120 & 0.0705 & -579 \\
\hline 20000 & 1363.2192 & 61700 & 1368.5933 & 62569 & 0.3942 & 869 \\
\hline
\end{tabular}

\section{Joint Flood Control Risk Evaluation of Cascade Reservoirs Considering Flood Prediction} Error

In joint flood control, the flood control operation mode of Three Gorges reservoir considering to Chenlingji is used, and now take flood process from June, 1st. 1998 to September 30th for example. With the flood frequency 1\%, the maximum 30-day flood volume error of Three Gorges flood process not more than $1 \%$ and the peak error within $1000 \mathrm{~m}^{3} / \mathrm{s}$ as control, discrete analysis is made by the standard deviation of prediction error $\mu_{X} \in[a,+\infty]$. It can be proved that control condition of flood volume and peak cannot be satisfied with $\mu_{X} \in(a,+\infty]$, and the value of $a$ is about 0.2 after analysis. The following Table 2 can be obtained by making joint operation calculation with standard deviation of prediction error $0.02,0.04,0.05,0.10,0.15,0.20$.

Table 2 Joint flood control of Xiluodu and Three Gorges with 100-year flood (1998 typical) under different prediction standard deviation

\begin{tabular}{|l|l|l|l|l|l|l|l|}
\hline Standard deviation of prediction error & 0.02 & 0.04 & 0.05 & 0.10 & 0.15 & 0.20 \\
\hline Zhicheng flood diversion [100 million $\left.\mathrm{m}^{3}\right]$ & 0.00 & 0.00 & 0.33 & 8.01 & 12.19 & 25.32 \\
\hline $\begin{array}{l}\text { Chenglingji flood diversion } \\
{\left[100 \text { million }^{3}\right]}\end{array}$ & 274.52 & 271.33 & 275.63 & 276.22 & 275.81 & 271.92 \\
\hline $\begin{array}{l}\text { Reservoir storage } \\
{\left[100 \text { million }{ }^{3}\right]}\end{array}$ & Xiluodu & 46.50 & 46.50 & 46.50 & 46.50 & 46.50 & 46.50 \\
\cline { 2 - 8 } & Three Gorges & 165.27 & 168.82 & 170.35 & 179.78 & 180.90 & 181.43 \\
\hline \multirow{2}{*}{ Reservoir storage degree [\%] $]$} & Xiluodu & 100 & 100 & 100 & 100 & 100 & 100 \\
\cline { 2 - 8 } & Three Gorges & 75 & 76 & 77 & 81 & 82 & 82 \\
\hline
\end{tabular}

The risk rate of water storage deficiency of cascade reservoirs is measured by storage degree of Xiluodu reservoir, because the joint flood control period of Xiluodu and Three Gorges joint is from June to September, but water storage time of Three Gorges is the beginning of October by operating regulation. It can be concluded from the table above that it is inevitable for Chenlingji to divert flood when encountering 100-year flood (1998 typical) and risk rate of reservoirs themselves and water storage deficiency are zero. Zhicheng need not to divert flood when standard deviation of prediction error is less than 0.05. But when standard deviation of prediction error is more than 0.05, Zhicheng begins to divert flood because the situation occurs that the sum of flood discharge of Three Gorges and flow between $\mathrm{Yi}$ and Zhi is more than safety flow $\left(56700 \mathrm{~m}^{3} / \mathrm{s}\right)$ of Zhicheng due to larger 
prediction deviation of flood process. Therefore, this paper takes the safety flow of Zhicheng as control point to analyze downstream flood control risk rate (diversion and storage risk rate of Jingjiang area). It can be seen from the table above when standard deviation of prediction error is 0.05 , expected flood diversion of Zhicheng is 0.033 billion $\mathrm{m}^{3}$, it shows the possibility to divert flood at the time, so standard deviation of prediction error is not more than 0.05 for guaranteeing that the Zhicheng is safety. Table 3 is obtained by calculating with the formula of model (8).

Table 3 Xiluodu and Three Gorges flood control joint operation risk rate with 100-year flood (1998 typical) under different prediction standard deviation

\begin{tabular}{|l|l|l|l|l|l|l|}
\hline Prediction error standard deviation & 0.02 & 0.04 & 0.05 & 0.10 & 0.15 & $\begin{array}{l}0.2 \\
0\end{array}$ \\
\hline Zhicheng flood dervision risk rate (\%) & 0.00 & 0.00 & 8.33 & 75.00 & 100 & 100 \\
\hline Three Gorges control level below-standard risk ratio (\%) & 0.00 & 0.00 & 41.67 & 83.33 & 91.67 & 100 \\
\hline Xiluodu reservoir fill storage ratio (\%) & 100 & 100 & 100 & 100 & 100 & 100 \\
\hline
\end{tabular}

It is shown in Table 3 that the maximum flood control risk rate of downstream (flood diversion risk rate of Zhicheng) is $8.33 \%$ when standard deviation of prediction error is less than 0.05.The maximum flood control risk rate is $75.00 \%$ when standard deviation of prediction error is less than 0.10 . The maximum flood control risk rate is $100 \%$ when standard deviation of prediction error is 0.15 . Therefore, when joint flood control of Xiluodu and Three Gorges encounters 100-year flood (1998 typical), there will be two critical points, that is 0.05 and 0.15 , and a certain flood diversion probability is existing within the interval [0.05, 0.15].Moreover, downstream flood control risk rate is little when it is less than 0.05 ; however, when it is more than 0.15 , flood diversion probability is much larger. Therefore, the value of prediction error in joint flood control operation has important significance to the downstream flood control risk.

\section{Conclusion}

Flood uncertainty is an important factor to consider in the process of joint flood control of cascade reservoirs, and the predicting flood is a useful and convenient method for making flood control decision. With the improvement of runoff prediction technique, especially that the short-term flood prediction technique has already had better precision, but it also faces a certain risk for the existence of prediction error. This paper takes joint flood control of cascade reservoirs as research object, and then gives the corresponding relationship between prediction error and joint flood control risk when reservoirs encounter a certain frequency typical flood by establishing risk index system of joint flood control and quantitative method of flood prediction error. By determining risk situation that joint flood control faces with this relationship, it can provide the important theoretical basis for flood control decision. However joint flood control risk index system and quantitative method of flood prediction error that this paper establishes are not absolute, and the relationship is more complex for the actual flood control of cascade reservoirs which faces more uncertain factors, therefore, different reservoirs need specific analysis according to the situation themselves.

\section{Acknowledgements}

This study was financially supported by the Open Research Fund of State Key Laboratory of Simulation and Regulation of Water Cycle in River Basin(China Institute of Water Resources and Hydropower Research)(IWHR-SKL-201420, 2016TS04), the 13th Five-Year National Key Program of China (2016YFC0402208, 2016YFC0402200), the National Science Foundation(51279210, 51279062, 51679088), the Major Consulting Strategic Project of Engineering Institute (2016-ZD-08-05) and the Fundamental Research Funds for the Central Universities (2016MS51). The authors are grateful to the anonymous reviewers for their comments and valuable suggestions. 


\section{References}

[1] Chih-Chiang Wei, Nien-Sheng Hsu (2008). Multireservoir real-time operations for flood control using balanced water level index method. Journal of Environmental Management 88:1624-1639.

[2] Peng Y, Li Y T, Zhang H W (2004). Multi-objective decision making model for coordinative dispatch of water and sediment in reservoir. Journal of Hydraulic Engineering 4:1-7.

[3] Fu G T (2008). A fuzzy optimization method for multicriteria decision making. An application to flood control operation.of reservoir Expert Systems with Applications 34:145-149.

[4] Huang Q, Fan R S, Shen J, et al (1996). Research on Joint Dispatching Model for Reservoirs on the Yellow River. Journal of Xi'an University of Technology 12:218-225.

[5] Wang D, Xu S B (2001). State of the Art of the flood control operation of multi-reservoir system. Advances in water science 12(1):118-123.

[6] Jiang Zhang, Mojdeh Delshad, Kamy Sepehrnoori (2007). Development of a framework for optimization of reservoir simulation studies. Journal of Petroleum Science and Engineering 59:135-146.

[7] Kyungrock Paik (2008). Analytical derivation of reservoir routing and hydrological risk evaluation of detention basins. Journal of Hydrology 352:191-201.

[8] R. O. Thomsen, I. Lerche (1997). Relative contributions to uncertainties in reserve estimates. Marine and Petroleum Geology 14:65-74.

[9] Diao Y F, Wang B D (2010). Risk analysis of operation mode of flood control with forecast information based on a combination of risk sources. Science China Technological Sciences. 53:1949-1956.

[10] Xiang Li, Shenglian Guo, Pan Liu, et al (2010). Dynamic control of flood limited water level for reservoir operation by considering inflow uncertainty. Journal of Hydrology 391:124-132.

[11] K. R. Suresh, P. P. Mujumdar (2004). A fuzzy risk approach for performance evaluation of an irrigation reservoir system. Agricultural Water Management 69:159-177.

[12] Wang L P, Zhang Y K, Ji C M, et al (2011). Simulate maximum entropy method and its application in reservoir flood risk Calculation. Journal of Hydraulic Engineering 42:27-32. 